\title{
Strukturanpassungsprogramme in Afrika - Einige Bemerkungen aus den aktuellen Erfahrungen der Schweiz
}

Les balbutiements de l'aide-programme macroéconomique

\section{Jürg Frieden}

\section{(2) OpenEdition}

Journals

Édition électronique

URL : http://journals.openedition.org/sjep/1156

DOI : $10.4000 /$ sjep. 1156

ISSN : 1663-9677

Éditeur

Institut de hautes études internationales et du développement

Édition imprimée

Date de publication : 1 janvier 1990

Pagination : 231-246

ISSN : $1660-5926$

\section{Référence électronique}

Jürg Frieden, «Strukturanpassungsprogramme in Afrika - Einige Bemerkungen aus den aktuellen Erfahrungen der Schweiz », Schweizerisches Jahrbuch für Entwicklungspolitik [En ligne], 9 | 1990, mis en ligne le 31 mars 2013, consulté le 08 septembre 2020. URL : http://journals.openedition.org/sjep/1156 ; DOI : https://doi.org/10.4000/sjep.1156

Ce document a été généré automatiquement le 8 septembre 2020

(C) The Graduate Institute 


\section{Strukturanpassungsprogramme in Afrika - Einige Bemerkungen aus den aktuellen Erfahrungen der Schweiz}

Les balbutiements de l'aide-programme macroéconomique

Jürg Frieden

\section{NOTE DE L'ÉDITEUR}

Zusammenfassung auf Deutsch. Volltext auf Französisch in Annuaire suisse de politique de développement: „Les balbutiements de l'aide-programme macroéconomique”, http:// aspd.revues.org/1323.

\section{RÉSUMÉS}

Die Strukturanpassungsprogramme in Afrika haben eine heftige Debatte über Sinn und Vorgehen wirtschaftspolitischer Anpassung ausgelöst. Gewisse Erfolge sind zu verzeichnen, doch fehlen noch weitgehend empirische Daten und die Unterschiede von Land zu Land sind zu beträchtlich, als dass verallgemeinernde Aussagen gemacht werden können. Eines aber haben Untersuchungen klar aufgezeigt: die komplexen Beziehungen zwischen volkswirtschaftlicher Neuorientierung und der Entwicklung der politischen und sozialen Strukturen eines Landes treten im Verlauf von Strukturanpassungsprogrammen deutlich hervor. Nach Ansicht des Autors 
hängt der langfristige Erfolg solcher Programme viel mehr von der Wandelfähigkeit der Gesellschaft $\mathrm{ab}$ als von der Effizienz der einen oder anderen wirtschaftspolitischen Massnahme. Der Beitrag erläutert Erfahrungen aus Strukturanpassungsprogrammen in Afrika, an denen sich die Schweiz beteiligt.

\section{AUTEUR}

\section{JÜRG FRIEDEN}

Economiste, Direction de la Coopération au développement et de l'aide humanitaire, Berne 